\title{
SOME FEATURES OF THERMAL MAGNETORESISTANCE OF A DIELECTRIC CRYSTAL WITH PARAMAGNETIC IMPURITIES
}

\begin{abstract}
The thermal magnetoresistance behavior of an insulating crystal doped with paramagnetic impurities is analyzed by using the expressions for the relaxation time obtained within the frames of a two-level impurity model [ $\left.{ }^{1}\right]$. Three characteristic kinds of behavior are considered. Necessary conditions are found under which the characteristic peculiarities of thermal magnetoresistance in dielectrics with various impurities are revealed. The results of the calculations of thermal magnetoresistance for $\mathrm{MgO}$ : $:\left(\mathrm{Cr}^{2+}:\right) \mathrm{Fe}^{2+}$ are compared with the experiment.
\end{abstract}

\section{Introduction}

Thermal conductivity of dielectrics containing paramagnetic ions as impurities depends at low temperature anomaly on the magnetic field:

(a) With the increase of the magnetic field strength, the thermal resistance $W_{H}$ rises at first as the Zeemann splitting $\hbar \omega_{0}$ of impurity magnetic levels tends towards the energy of dominant phonons $(\hbar \omega=3.8 \mathrm{kT}$ ) and then falls smoothly as $\hbar \omega_{0}$ gets out of resonance. Such peculiarities were first observed in concentrated crystals with paramagnetic ions [ $\left.{ }^{2}\right]$.

(b) In the case of a complex structure of the levels, the thermal magnetoresistance may have several maxima of various intensities $\left[{ }^{3}\right]$. Often, especially in high fields, thermal conductivity may exceed its zero-field value $K(T, H=0)=1 / W_{0}$. That is possible when zero-field splitting of impurity levels is present; the magnetic field distorts the structure of these levels and, therefore, can decrease the initial resonant phonon scattering $\left[{ }^{4}\right]$.

(c) Paramagnetic ions scatter resonantly phonons of certain frequency which can be changed by means of an external magnetic field. As a result, thermal magnetoresistance is highly sensitive to the existence of other non-magnetic processes of the resonant scattering of phonons and may be used for their study [5].

The calculation of the peculiarity of type (a), with the use of a phenomenological expression for the shape of spin resonance lines, was first carried out by Orbach [ $\left.{ }^{6}\right]$. More recently detailed calculations for Kramer's and non-Kramer's paramagnetic salts were made with the application of the Green functions $\left.{ }^{7}\right]$ and the Kubo formula $\left.{ }^{8}\right]$. Semi-phenomenological calculation of the peculiarities of type (b) were presented in $\left[{ }^{4,9}\right]$. Note that in $[4,7,8]$ also the effect of the Rayleigh impurity scattering on the magnetic field dependence of thermal resistance was considered. It was shown that the Rayleigh scattering may strongly distort the magnetic dependence curves while it does not lead to the appearance of new pecutiarities on these curves. 
In the present paper the calculations of the peculiarities of (a), (b) and (c) types are presented. We show that: (1) resonant scattering on non-magnetic impurities produces a sharp depression on the magnetic dependence of thermal resistance (peculiarity of (c) type) only if some necessary conditions are fulfilled; (2) all the peculiarities of types (a), (b) and (c) can be obtained by means of a suitable choice of inverse relaxation times corresponding to various magnetic transitions.

\section{Model}

Let us consider a cubic $\mathrm{MgO}$ type crystal with a small concentration $\left(c_{i} \ll 1\right)$ of various (magnetic and non-magnetic) impurities. The thermal conductivity of such system has the form [ $\left.{ }^{1}\right]$ :

$$
\begin{gathered}
K(T, H)=\frac{v_{0}^{2}}{a^{3}} \int d \omega^{2} C\left(\omega^{2}\right) \tau\left(\omega^{2}\right) \varrho\left(\omega^{2}\right), \\
C\left(\omega^{2}\right)=k(\beta \omega)^{2} \mathrm{e}^{\beta \omega}\left(\mathrm{e}^{\beta \omega}-1\right)^{-2}, \\
\tau^{-1}\left(\omega^{2}\right)=\tau_{0}^{-1}(\omega)+\tau_{\alpha}^{-1}(\omega)+\tau_{M}^{-1}(\omega, H),
\end{gathered}
$$

where $\beta=\hbar / k T, k$ is the Boltzmann constant, $\varrho\left(\omega^{2}\right)$ - density of squared frequencies, $v_{0}-$ mean velocity of phonons, $a$ - lattice constant, $\tau_{0}^{-1}-$ inverse relaxation time for a nominally pure crystal, $\tau_{\alpha}^{-1}$ describes resonant scattering in zero magnetic field. The inverse relaxation time for a particular magnetic transition will be considered within the frames of a two-level model of the impurity atom, making use of the previously obtained expression for $\tau_{M}^{-1}\left[{ }^{1}\right]$ :

$$
\begin{gathered}
\tau_{M}^{-1}(\omega, H)=\frac{c_{i} \alpha^{2} \omega_{0} \eta}{\pi \omega \varrho\left(\omega^{2}\right)} \frac{2 \omega \Gamma(\omega) \operatorname{Im} g_{F}(\omega)}{\left(\omega^{2}-\Omega_{0}^{2}\right)^{2}+4 \omega^{2} \Gamma^{2}(\omega)}, \\
\Omega_{0}^{2}(\omega)=\omega_{0}^{2}-\alpha^{2} \omega \operatorname{Re} g_{F}^{T}(\omega)+c_{i} \alpha^{2} \omega_{0} \eta \operatorname{Re} g_{F}(\omega), \\
2 \omega \Gamma(\omega)=\alpha^{2}\left(\omega \xi-c_{i} \omega_{0} \eta\right) \operatorname{Im} g_{F}(\omega) .
\end{gathered}
$$

Here $\hbar \omega_{0}=g \mu H, \alpha$ is the spin-phonon interaction constant, $g$ - spectroscopic splitting factor, $\mu$ - Bohr's magneton, $\xi(\omega)=\operatorname{cth}\left(\hbar_{\omega} / 2 k T\right), \eta(\omega)=$ $=\operatorname{th}\left(\hbar \omega_{r} / 2 k T\right), \omega_{r}^{2}=\Omega_{0}^{2}\left(\omega_{r}\right), g_{F}-$ Green's function of the crystal projected onto the $F_{1 g}$ (or $F=F_{2 g}$ ) irreducible representation. At low temperature where the Debye approximation holds $\operatorname{Re} g_{F}^{T}(\omega)=\left(\omega / \omega_{D}\right) \operatorname{Re} g_{F}(\omega)$, $\operatorname{Re} g_{F}(\omega)=3\left(1 / \omega_{D}^{2}+2.84 \omega^{2} / \omega_{D}^{4}\right), \quad \operatorname{Im} g_{F}(\omega)=2 \pi \varrho\left(\omega^{2}\right) \sin ^{2} \frac{\pi \omega}{\omega_{D}}, \quad \varrho\left(\omega^{2}\right)=$ $=3 \omega / 2 \omega_{D}^{3}, \omega_{D}$ is the Debye frequency. Besides, in the following we shall, as far as possible, use the values of the parametric characteristic of $\mathrm{MgO}$. That will allow us to compare qualitatively some of our results with the corresponding experiments for $\mathrm{MgO}:\left(\mathrm{Cr}^{2+}:\right) \mathrm{Fe}^{2+}\left[{ }^{9}\right]$. We shall especially use the values $\tau_{0}^{-1}=\tau_{b}{ }^{-1}+\tau_{n}{ }^{-1}$, where $\tau_{b}{ }^{-1}=3.5 \cdot 10^{6} \mathrm{~s}^{-1}$ is the boundary scattering and $\tau_{n}^{-1}=10^{5} \mathrm{C} \omega^{4} / \omega_{D}^{3}-$ due to the Rayleigh phononimpurity (caused by the change of the mass and force constants) scattering on different (including also non-identified) impurities of the sample; $\Theta=\hbar \omega_{D} / k=945 \mathrm{~K}$; for other parameters see also [9,1]. 


\section{Numerical Results and Discussion}

Usual peculiarities of type (a) calculated for Kramer's and non-Kramer's ions are shown in Fig. 1 (dash-dotted and solid lines, respectively). These curves qualitatively reflect the structure of non-magnetic $\left(\tau^{-1}-\tau_{M}{ }^{-1}=\right.$ $=\tau_{N}{ }^{-1}$ ) relaxation time. Indeed, if one takes into account that at small $\Delta=W_{H} / W_{0}-1$ the relative change $\Delta k / k_{0}=W_{0} / W_{H}-1 \simeq-\Delta$, then, assuming a $\delta$-shaped form for magnetic resonance $\left(\tau_{M}{ }^{-1}=\infty\right.$, when $\omega_{0}-\delta \omega / 2<$ $<\omega<\omega_{0}+\delta \omega / 2$ and $\tau_{M}{ }^{-1}=0$ for all other $\left.\omega\right)$, we get according to (1) and (4)

$$
\begin{gathered}
\Delta\left(\omega_{0}\right)=\frac{v_{0}^{2}}{a^{3}} C\left(\omega_{0}\right) \tau_{N}\left(\omega_{0}\right) \varrho\left(\omega_{0}^{2}\right) 2 \omega_{0} \delta \omega, \\
\delta \omega=2 \Gamma\left(\omega_{0}\right) .
\end{gathered}
$$

Magnetic fields $H_{m}$ for which thermal resistance achieves the maximum value are in a good agreement with the condition of resonance for dominant phonons: $H_{m}=3.8 k T / g \mu=16.6 T$ (in kOe; $I=1 ; 1.5 ; 2^{\circ} \mathrm{K}$ ). An increase in the maximum value of thermal resistance with the rise of temperature is evidently related to the increase in the halfwidth $\Gamma(x)=$ $=\Gamma\left(\omega / \omega_{D}=\frac{3}{2} \pi v\left(x \xi-c_{i} x \eta\right) \sin ^{2} \pi x \quad\left(v=\alpha^{2} / \omega_{D}^{3} ; \quad x=\omega_{D} / \omega_{D}\right) . \quad\right.$ Indeed, since $c_{i} \ll 1$ and $x_{0}=\omega_{0} / \omega_{D} \ll 1$, then $\Gamma\left(x_{0}\right) \simeq a x_{0}{ }^{3} \xi\left(x_{0}\right) \quad\left(a=3 \pi^{3} v / 2\right)$ and, with the increase of $x_{0}, \Gamma\left(x_{0}\right)$ grows like $a x_{0}{ }^{3}$ at $\gamma x_{0} / 2>1 \quad(\gamma=\Theta / T)$ or like $2 a x_{0}^{2} T / \Theta$ at $\gamma x_{0} / 2<1$. At the point $x_{m}=g \mu H_{m} / \bar{n}_{\omega_{D}}=3.8 T / \Theta, \gamma x_{m} / 2=$ $=1.9>1$ and $\Gamma\left(x_{m}\right)=a x_{m}{ }^{3} \infty T^{3}$, which is reflected in the behavior of $\Delta\left(x_{m}\right)$ for non-Kramer's ions in Fig. 1. For Kramer's ions $\Delta\left(x_{m}\right)$ is somewhat shifted towards higher fields owing to the interaction $v$ on the magnetic field.

If a resonant non-magnetic scattering of phonons $\left(\tau_{N}{ }^{-1}=\tau_{0}{ }^{-1}+\tau_{\alpha}{ }^{-1}\right.$; $\tau_{\alpha}^{-1} \neq 0$ ) around some frequency $\omega_{r}$ takes place, then according to (7), the behavior of $\Delta\left(\omega_{0}\right)$ reveals this frequency. Fig. 1 (dashes and dots) presents the results of the calculations for the peculiarities of type (c) for two cases $\tau_{\alpha}^{-1}=\tau_{s}^{-1}$ and $\tau_{\alpha}^{-1}=\tau_{L}^{-1}$. Here the former case corresponds to the resonant scattering of phonons in the zero magnetic field by $\mathrm{Cr}^{2+}$ ions, for which we used the expression and values of the parameters from [1]. In this case on the curve $W_{H} / W_{0}$ a sharp depression appears, indicating the growth of thermal conductivity. The position of the arising minimum $\left(H_{r}=24 \mathrm{kOe}\right)$ is determined precisely by the frequency $\omega_{r}=g \mu H_{r} / \hbar=5.28 \mathrm{~cm}^{-1}$ and does not depend on the tempera-

Fig. 1. Thermal magnetoresistance of a cubic crystal with various impurities.

Solid lines - for non-Kramer's ions: $c_{\mathrm{Fe}}=$ $=95 \cdot 10^{-7}, v=0.02, \tau_{\alpha}^{-1}=0$; dashed and dotted lines (at $T=1 \mathrm{~K})$ - the same with the account of $\tau_{\alpha}^{-1}=\tau_{s}^{-1}, \quad c=5 \cdot 10^{-7}, v=0.33, \omega_{r}=5.2 \mathrm{~cm}^{-1}$ and $\tau_{\alpha}^{-1}=\tau_{L}^{-1}, c_{L}=4 \cdot 10^{-3}, \varepsilon=10$ respectively; dash-dotted line (at $T=1 \mathrm{~K}$ ) - for Kramer's ions: $c_{\mathrm{Fe}}=95 \cdot 10^{-7}, \quad v=4.35 \cdot 10^{-5} \cdot H^{2}, \quad \tau_{\alpha}^{-1}=0$.

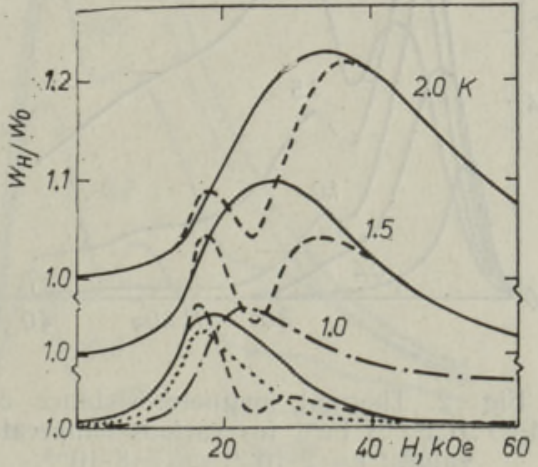


ture. In the second case, $\tau_{L}$ is the mass-defect scattering relaxation rate for which a well-known expression (see, e. g., $\left[{ }^{10}\right]$ ) is applied with a large value of $\varepsilon=m^{\prime} \mid m-1=10$. But even in this case, for the region of temperatures under study $(T \leqslant 5 \mathrm{~K})$, the resonant frequency greatly exceeds the frequency of dominant phonons and the corresponding region of magnetic fields $\hbar \omega_{r}=0.2 \hbar \omega_{D} \gg 3.8 k T=g \mu H_{m}$. As a result, instead of the depression, only a weakening of thermal resistance is observed mainly to the right of the maximum (i.e., at $H>H_{m}$ ). In the other extreme case $\hbar \omega_{r} \ll g \mu H_{m}$, a weakening of thermal magnetoresistance takes place in the region of weak fields $H<H_{m}$.

The values of the parameters $g$ and $v$ used for $\tau_{M}{ }^{-1}$ were chosen so that they would actually correspond to the magnetic transition in $\mathrm{Fe}^{2+}$ ion in $\mathrm{MgO}$. For this transition the projection of the whole spin on the axis $z / / \vec{H}$ is changed by unity $(\Delta M=1)$, and the ground triplet state of $\mathrm{Fe}^{2+}$ in $\mathrm{MgO}$ has $g$-factor equal to 3.4 . Besides this transition $(\Delta M=1)$ there is a stronger transition with $\Delta M=2\left(v_{\Delta M=2}=0.16\right)$ in this system. The $g$-factor of this transition equals 6.8 and, thus, a weak transition $(\Delta M=1)$ is observed for the field which is roughly twice that for $\Delta M=2$ transition. Note that in $\mathrm{MgO}$, besides $\mathrm{Fe}^{2+}$ ions, there are often $\mathrm{Cr}^{2+}$ ions present, which also resonantly scatter phonons. Thus, the thermal magnetoresistance of $\mathrm{MgO}:\left(\mathrm{Cr}^{2+}:\right) \mathrm{Fe}^{2+}$ has quite a complicated form $\left[{ }^{9}\right]$, which is characteristic of the peculiarities of type (b). In order to obtain such peculiarities let us assume the phonon scattering due to various transitions $\Delta M=1$ and $\Delta M=2$ to occur independently of each other (this assumption is evidently justified only at very low temperatures, $\left.k T \leqslant \hbar \omega_{0}=g \mu H\right)$. Then the magnetic inverse relaxation time may be represented in the form $\tau_{M}^{-1}=\tau_{\Delta M=1}^{-1}+\tau_{\Delta M=2}^{-1}$. This expression was used for the calculation of thermal magnetoresistance of $\mathrm{MgO}:\left(\mathrm{Cr}^{2+}:\right)$ $\mathrm{Fe}^{2+}$ (thermal conductivity of $\mathrm{MgO}: \mathrm{Fe}^{2+}$ and $\mathrm{MgO}: \mathrm{Cr}^{2+}$ in the absence of the magnetic field was studied in [ $\left.{ }^{11}\right]$ and $\left[{ }^{1}\right]$, respectively). The results of the calculations for two different values of the concentrations of $\mathrm{Fe}^{2+}$ ions are presented in Figs 2 and 3. In the case of small concentrations (Fig. 2) two bands caused by transitions $\Delta M=1$ and 2 are

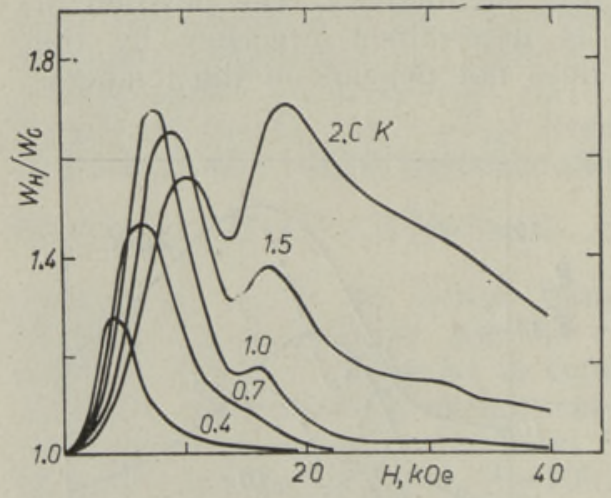

Fig. 2. Thermal magnetoresistance of $\mathrm{MgO}:\left(\mathrm{Cr}^{2+}:\right) \mathrm{Fe}^{2+}$ for various temperature values; $c=2 \cdot 10^{-6}, c_{\mathrm{Fe}}=8 \cdot 10^{-6}$.

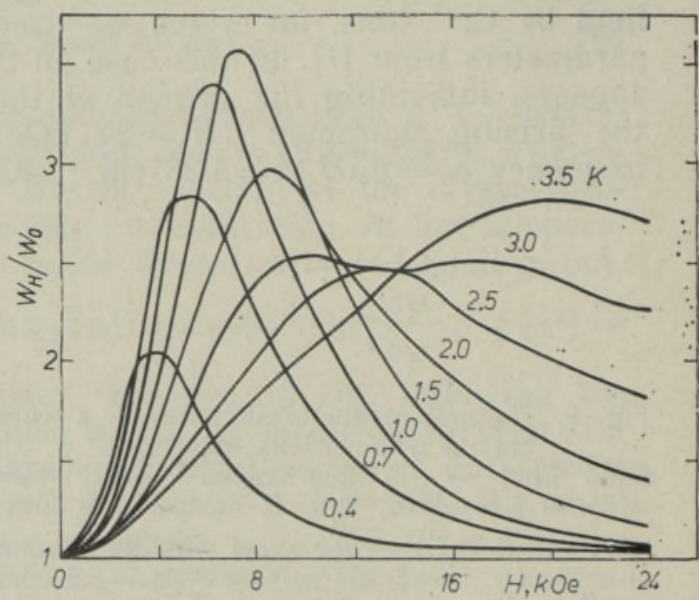

Fig. 3. The same as in Fig. 2 for $c=10^{-5}$, $c_{\mathrm{Fe}}=9 \cdot 10^{-5}$. 
clearly seen. The intensity of the bands is strongly redistributed with the rise of temperature. Band maxima are shifted, but the ratio between the values of magnetic fields for the transition $\Delta M=1$ and the corresponding values of the fields for the transition $\Delta M=2$ remain unchanged $(\sim 2)$. For $H \simeq 25$ kOe a weak depression of curves $W_{H} / W_{0}$ is observed. This depression is caused by $\mathrm{Cr}^{2+}$ ions while its weakness is connected with the reduction of the zero-field resonant scattering of phonons by $\mathrm{Cr}^{2+}$ ions at strong magnetic transitions $\Delta M=1$ and 2 in $\mathrm{Fe}^{2+}$ ions. In particular, at high concentrations of $\mathrm{Fe}^{2+}$ ions (Fig. 3) the scattering by chromium ions is weakly revealed only for the highest values of temperature in our calculations, $T=3.0$ and $3.5 \mathrm{~K}$. In this case also the magnetic transition $\Delta M=1$ is strongly reduced. It is observable only at $2.5,3.0$ and $3.5 \mathrm{~K}$. It is worthwhile noting that in the presence of two magnetic transitions the maxima in $W_{H} / W_{0}$ curves corresponding to these transitions behave in a different manner when the temperature rises. The high-field peak $(\Delta M=1$ in our case) rises monotonously, whereas the low-field peak $(\Delta M=2)$ begins to fall reaching certain temperature ( 1 and $1.5 \mathrm{~K}$ in Figs 2 and 3 , respectively). That is an evidence of the fact that further broadening of the resonance width in $\tau_{\Delta M=2}^{-1}$, causing the increase in the intensity of the transition $\Delta M=2$, can no more compete with the capture of phonons by the other scattering channel $(\Delta M=1)$.

As the resonant scattering of phonons by $\mathrm{Cr}^{2+}$ ions for the cases represented in Figs 2 and 3 is strongly reduced, we carried out special calculations of $W_{H} / W_{0}$ at various concentrations of $\mathrm{Cr}^{2+}$ ions. In this we also took into account the Rayleigh phonon-impurity scattering by $\mathrm{Cr}^{2+}$ ions and other (non-identified) impurities $\left(\tau_{n}^{-1} \neq 0\right)$ which, according to $\left[{ }^{9}\right]$, is changed from sample to sample. It appeared that the zero-field resonant scattering by $\mathrm{Cr}^{2+}$ (depression at $23 \mathrm{kOe}$ ) is revealed only for a certain concentration range $\left(c=5 \div 20 \cdot 10^{-7}\right)$ of chromium ions (see Fig. 4). Further increase of the concentration of chromium, as shown in $\left.{ }^{1}\right]$, leads to the reduction of the resonant scattering by $\mathrm{Cr}^{2+}$ ions on the account of a simultaneous increase in the Rayleigh phonon-impurity scattering $\tau_{n}{ }^{-1}$. The Rayleigh scattering itself gives rise to a smooth decrease in $W_{H} / W_{0}$ almost in the whole region of magnetic fields under study. Let us also mention that in the cases when the resonant scattering by chromium is most noticeable $(c=$ $\left.=5 \div 20 \cdot 10^{-7}\right)$, also an es. sential improvement of the

Fig. 4. Thermal magnetoresistance of $\mathrm{MgO}:\left(\mathrm{Cr}^{2+}:\right) \mathrm{Fe}^{2+}$ at $T=1.5 \mathrm{~K}$ for various concentrations $c=(0,5,20$, $80) \cdot 10^{-7}$ and $c_{\mathrm{Fe}}=(100,95,80,20)$. $\cdot 10^{-7}$ of $\mathrm{Cr}^{2+}$ and $\mathrm{Fe}^{2+}$ ions, respectively; dotted lines, $W_{H} / W_{0}$ at $c=0$ and $c_{\mathrm{Fe}}=95 \cdot 10^{-7}$.

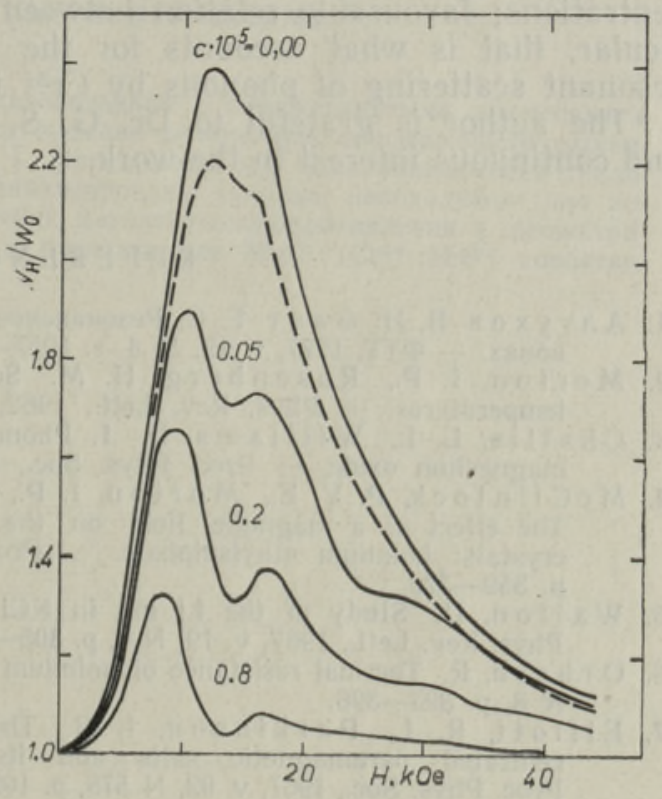


resolution of magnetic transitions $\Delta M=1$ and 2 is manifested. It is especially clearly revealed in the comparison of the dotted curve and the curve for $c=5 \cdot 10^{-7}$ in Fig. 4. It is important that the concentration of $\mathrm{Fe}^{2+}$ for these two cases is the same.

As a whole, the obtained results of Figs 2, 3 and 4 describe qualitatively correctly the dependence of the thermal conductivity of $\mathrm{MgO}:\left(\mathrm{Cr}^{2+}:\right) \mathrm{Fe}^{2+}$ on the magnetic field. However, due to the enforced use of approximate values of the parameters $v$ and $c_{i}$ : for $\mathrm{Cr}^{2+}$ and $\mathrm{Fe}^{2+}$ ions, and also due to a number of restrictions made in the choice of the model, the positions and intensity of particular peaks on curves $W_{H} / W_{0}$ at some temperature values do not agree with the experiment quantitatively. In particular, it is necessary to take into consideration that in a general case the transitions $\Delta M=1$ and 2 are not independent. Besides, the direct comparison is hampered by the anisotropy of thermal magnetoresistance, called forth by the dependence of scattering cross-section on: (a) the angle between the directions of the heat current and the magnetic field, and (b) the angles between the magnetic field and crystallographic axes $\left[{ }^{9}\right]$. Though the theory allows, in principle, to take into account the anisotropy of $W_{H} / W_{0}$, in this case concrete calculations bring about serious complications arising due to a number of unknown constants different from zero.

\section{Conclusion}

In summary, we have shown that when using a proper set of simple expressions for the inverse relaxation times corresponding to a two-level atom model, it is possible to obtain various types of the behavior of thermal magnetoresistance of dielectrics with magnetic impurities (peculiarities of (a), (b) and (c) types). The obtained results describe qualitatively well the experimental data. Besides, it follows from the previous analysis that the peculiarities of type (c) are revealed only with a number of necessary conditions being satisfied: correspondence of spectral, magnetic and temperature regions; characteristic impurity concentrations; favourable relation between interaction parameters. In particular, that is what accounts for the appearance of relatively weak resonant scattering of phonons by $\mathrm{Cr}^{2+}$ ions in magnetic experiment [ $\left.{ }^{9}\right]$.

The author is grateful to Dr. G. S. Zavt for numerable discussions and continuous interest in the work.

\section{REFERENCES}

1. Алтух ов В. И., 3 а в т Г. С. Резонансное рассеяние фононов на парамагнитных ионах. - ФТТ, 1977 , т. 19, № 4, с. 1057-1064.

2. Morton, I. P., Rosenberg, H. M. Scattering of phonons by spins at low temperatures. - Phys. Rev. Lett., 1962, v. 8, N 5, p. 200-201.

3. Challis, L. I., William s, D. I. Phonon scattering by paramagnetic ions in magnesium oxide. - Proc. Phys. Soc., 1966, v. 88, N 559, p. 131-134.

4. McClintock, P. V. E., Morton, I. P., Orbach, R., Rosenberg, H. M. The effect of a magnetic field on the thermal conductivity of paramagnetic crystals: holmium ethylsulphate. - Proc. Roy. Soc., 1967, v. A298, N 1454, p. $359-378$.

5. W a It o n, D. Study of the $\mathrm{Li}$ ion in $\mathrm{KCl}$ using the spin-phonon interaction. Phys. Rev. Lett., 1967, v. 19, N 6, p. 305-307.

6. O r b a c h, R. Thermal resistance of holmium sulphate. - Phys. Rev. Lett., 1962, v. 8, N 8, p. 393-396.

7. Elliott, R. I., Parkinson, I. B. Theory of spin-phonon coupling in concentrated paramagnetic salts and its effect on thermal conductivity. Proc. Phys. Soc., 1967, v. 92, N 578, p. 1024-1039. 
8. Иолин Е. М. Влияние спин-фононного взаимодействия на теплопроводность парамагнетика, - ФТТ, 1970, т. 12, № 4, с. 1159-1166.

9. Challis, L. I., McConachie, M. A., Williams, D. I. The observation of phonon scattering by paramagnetic ions in magnesium oxide by thermal mag. netoresistance measurements. - Proc. Roy. Soc., 1969, v. A310, N 1503, p. $493-524$.

10. 3 а в т Г. С., Алту х ов В. И. Особенности фононной теплопроводности кристаллов с узкими псевдолокальными колебаниями. - ФТТ, 1973, т. 15, № 3, с. $766-768$.

11. Morton, I. P., Lewis, M. F. Effect of iron impurities on the thermal conductivity of magnesium oxide single crystals below room temperature. - Phys. Rev., 1971, v. 3, N 2, p. 552-559.
Academy of Sciences of the Estonian SSR,
Received Institute of Physics
Mar. 5, 1977

\section{ALTUHHOV}

\section{PARAMAGNETILISTE LISANDITEGA DIELEKTRIKUTE MAGNETILISE SOOJUSTAKISTUSE ISEÄRASUSED}

On arvutatud paramagnetiliste lisanditega dielektrikute soojustakistus magnetväljas, kusjuures on kasutatud ioononite hajumist kahe nivooga aatomitel kirjeldavaid relaksatsiconiaegu. Esineb kolme tüüpi soojustakistuse sōltuvust magnetväljast. On analüüsitud mitmesuguste lisanditega dielektrikute soojustakistuse karakteersete iseärasuste olemasoluks vajalikke tingimusi. MgO :( $\left.\mathrm{Cr}^{2+}:\right) \mathrm{Fe}^{2+}$ magnetilise soojustakistuse arvutuse tulemusi on võrreldud katseandimetega.

В. АЛТУХОВ

\section{ОСОБЕННОСТИ МАГНИТОТЕПЛОСОПРОТИВЛЕНИЯ ДИЭЛЕКТРИКОВ С ПАРАМАГНИТНЫМИ ПРИМЕСЯМИ}

Рассчитано магнитотеплосопротивление диэлектриков с парамагнитными примесями с использованием выражения для обратного времени релаксации, описывающего рассеяние фононов на двухуровневом атоме [1]. Определены три вида зависимости теплосопротивления от магнитного поля. Проанализированы условия, необходимые для появления характерных особенностей поведения магнитотеплосопротивления в диэлектриках с различными примесями. Результаты расчетов для $\mathrm{MgO}:\left(\mathrm{Cr}^{2+}:\right) \mathrm{Fe}^{2+}$ сопоставлены с данными экспериментов. 